Boston University School of Law Scholarly Commons at Boston University School of Law

Faculty Scholarship

Fall 2013

\title{
Approval and Withdrawal of New Antibiotics and Other Antiinfectives in the U.S., 1980-2009
}

\author{
Kevin Outterson \\ Boston Univeristy School of Law \\ John H. Powers \\ George Washington University \\ Enrique Seoane \\ International Center for Pharmaceutical Economics and Policy \\ Rosa Rodriguez-Monguio \\ University of Massachusetts Amherst \\ Aaron S. Kesselheim \\ Brigham and Women's Hospital/Harvard Medical School
}

Follow this and additional works at: https://scholarship.law.bu.edu/faculty_scholarship

Part of the Health Law and Policy Commons

\section{Recommended Citation}

Kevin Outterson, John H. Powers, Enrique Seoane, Rosa Rodriguez-Monguio \& Aaron S. Kesselheim, Approval and Withdrawal of New Antibiotics and Other Antiinfectives in the U.S., 1980-2009, 41 Journal of Law, Medicine and Ethics 688 (2013).

Available at: https://scholarship.law.bu.edu/faculty_scholarship/6 


\title{
BU School of Law
}

\section{APPROVAL AND WITHDRAWAL OF NEW ANTIBIOTICS AND OTHER ANTIINFECTIVES IN THE U.S., 1980-2009}

\author{
Journal of Law, Medicine and Ethics, p. 688, Fall 2013
}

Boston University School of Law Working Paper No. 13-47

(September 30, 2013)

Kevin Outterson

Boston University School of Law

John H. Powers

George Washington University

Enrique Seoane

Ohio State University

Rosa Rodriquez-Monguio

University of Massachusetts

Aaron S. Kesselheim

Brigham and Woman's Hospital / Harvard Medical School; Harvard University - Edmond J. Safra Center for Ethics

This paper can be downloaded without charge at:

http://www.bu.edu/law/faculty/scholarship/workingpapers/2013.html 


\title{
Approval and Withdrawal of New Antibiotics and Other Antiinfectives in the U.S., 1980-2009
}

\author{
Kevin Outterson, John H. Powers, Enrique Seoane-Vazquez, \\ Rosa Rodriguez-Monguio, and Aaron S. Kesselheim
}

A ntibiotic use triggers evolutionary and ecological responses from bacteria, leading to antibiotic resistance and harmful patient outcomes. ${ }^{1}$ Two complementary strategies support long-term antibiotic effectiveness: conservation of existing therapies and production of novel antibiotics. ${ }^{2}$ Conservation encompasses infection control, antibiotic stewardship, and other public health interventions to prevent infection, which reduce antibiotic demand. ${ }^{3}$ Production of new antibiotics allows physicians to replace existing drugs rendered less effective by resistance. ${ }^{4}$

In recent years, physicians and policymakers have raised concerns about the pipeline for new antibiotics, pointing to a decline in the number of antibiotics approved since the 1980s. ${ }^{5}$ This trend has been attributed to high research and development costs, low reimbursement for antibiotics, and regulatory standards for review and approval. ${ }^{6}$ Professional societies and researchers around the world have called for renewed emphasis on antimicrobial stewardship, ${ }^{7}$ while also supporting antibiotic research and development through grants, changes to intellectual property laws to extend market exclusivity periods, and modification of premarket testing regulations to reduce antibiotic development time and expenses. ${ }^{8}$ In the US, these legislative efforts recently culminated with the enactment of the Generating Antibiotic Incentives Now (GAIN) section of the Food and Drug Adminis- tration Safety and Innovation Act of 2012, which was intended to promote the discovery of new antibiotics by providing five years of additional market exclusivity for new "qualified infectious disease products." The Food and Drug Administration Safety and Innovation Act also created a fast track system to reduce clinical trial development time for breakthrough drugs, including new antibiotics..$^{10}$ The European Union has also been active in considering new therapeutic development incentives together with other efforts such as enhanced antimicrobial stewardship and support for basic research. ${ }^{11}$

While incentives for antibiotic development may hasten the arrival of a larger number of drugs, public health will be best served if these new drugs have high clinical utility, discrete mechanisms of action and narrow spectrums to delay resistance, and welldefined safety and efficacy profiles. ${ }^{12}$ In recent years, however, there have been numerous high-profile examples of approved antibiotics found to have safety concerns, including trovafloxacin, which was withdrawn from the US market, and telithromycin, which had two indications withdrawn in self-resolving diseases, but remains available for treatment of community-acquired pneumonia despite well-known safety issues. Studies reporting simple counts of new antibiotic approvals do not adequately consider the clinical impact of the antibiotics - or subsequent safetyrelated withdrawals - and therefore may provide

Kevin Outterson, J.D., LL.M., is a Professor of Law at Boston University. John H. Powers, M.D., FACP, FIDSA is an Associate Clinical Professor of Medicine, George Washington University School of Medicine. Washington, DC. Enrique Seoane-Vazquez, Ph.D., is an Associate Professor in the Division of Pharmaceutical Sciences, and Director of the International Center for Pharmaceutical Economics and Policy at the Massachusetts College of Pharmacy and Health Sciences, Boston, MA. Rosa RodriguezMonguio, Ph.D., is an Associate Professor in the School of Public Health and Health Sciences at the University of Massachusetts, Amherst. Aaron S. Kesselheim, M.D., J.D. M.P.H., is an Assistant Professor of Medicine in the Division of Pharmacoepidemiology and Pharmacoeconomics in the Department of Medicine at Brigham and Women's Hospital and Harvard Medical School. 
an incomplete picture of antibiotic development. To better understand recent trends, we analyzed three decades of FDA antibiotic approvals, together with markers of antibiotic safety and efficacy. To put antibiotic trends in context, we compared these results with approvals and withdrawals in other drug classes, including other antiinfectives. Comparisons to other
NMEs and BLAs were withdrawn from the US market as of December 31, 2011. Withdrawals were identified in one of three ways: (1) publication by FDA of a notice of withdrawal of approval in the Federal Register; (2) listing of the product in the Orange Book discontinuation section; or (3) removal of the product from the Orange Book approved applications section.

\section{Studies reporting simple counts of new antibiotic approvals do not adequately consider the clinical impact of the antibiotics - or subsequent safety-related withdrawals - and therefore may provide an incomplete picture of antibiotic development. To better understand recent trends, we analyzed three decades of FDA antibiotic approvals, together with markers of antibiotic safety and efficacy. To put antibiotic trends in context, we compared these results with approvals and withdrawals in other drug classes, including other antiinfectives.}

drug classes, such as cardiovascular drugs, can illuminate whether the outcomes of our study are unique to antibiotics or are common across several drug classes. Comparisons between antibiotics, antivirals and antiretrovirals, and other antiinfectives can also identify shifts in innovation within the antiinfective therapeutic class.

\section{Data}

\section{Drug Classifications}

From publicly available data on the FDA website Drugs@FDA, ${ }^{13}$ we identified all new drug applications for new molecular entities (NMEs) and new biologic license applications (BLAs) approved by the FDA from January 1, 1980 through December 31, 2009. The dates of approval were confirmed using the Approved Drug Products with Therapeutic Equivalence Evaluations (Orange Book). We then classified each drug based on its approved indication into a class of the Anatomic Therapeutic Chemical (ATC) classification system maintained by the WHO Collaborating Centre for Drug Statistics Methodology of the Norwegian Institute of Public Health. ${ }^{14}$ "Antiinfectives for systemic use" (class $J$ ) were further subclassified into three categories: "antibiotics for systemic use" (subclass J01), "antivirals for systemic use" (subclass J05), and "other antiinfectives" (all other subclasses, which include antimycotics and vaccines). From the same FDA databases, we identified whether each drug in our sample was granted priority review or orphan drug status by the FDA. Finally, using methods described by Qureshi et al., ${ }^{15}$ we determined which

\section{Characterization of Antibiotic Withdrawals}

For all withdrawn drugs in the antibiotic subclass J01, we then identified the specific date when these withdrawn drugs were discontinued from the US market. Withdrawal of approval of an antibiotic generates a specific announcement by the FDA, as described above. However, for some antibiotics, the company discontinued widespread sales of the antibiotic many years before regulatory withdrawal. Such informal discontinuations are rarely accompanied by a formal announcement. We therefore defined the date of discontinuation as the calendar quarter in which commercial sales in the US dropped below US $\$ 100,000$, using data from IMS MIDAS (data available for 19932009 only). When IMS data were not available, we used the date of the official FDA regulatory action.

We then categorized whether each antibiotic withdrawal was associated with a safety issue. A safetyrelated withdrawal was defined as a withdrawal that occurred within a year after new safety-related warnings were added to the drug label, or one described as such in regulatory notices published in the Federal Register and other government reports, public company filings with the Securities and Exchange Commission's EDGAR database, or other announcements found in the Westlaw databases.

Finally, we noted the peak US sales and the sponsoring company for all withdrawn antibiotics. We characterized an antibiotic as "commercially successful" if it achieved US sales exceeding \$100 million (2010 dollars) in any calendar year. All data were analyzed descriptively. 


\section{Results}

The FDA approved 815 NMEs and BLAs during the study period, with a peak in the late 1990s. We found that 35 new drugs in the class of antiinfectives were approved in the 1980 s (16\% of all drug approvals), as compared to 49 in the 1990 s (15\%), and $27(11 \%)$ in the 2000s. Among the subclass of antibiotics, 61 NMEs were approved overall, with the greatest number approved in the 1980 s $(29,13 \%$ of all drug approvals), fewer in the 1990s (23, 7\%) and still fewer the 2000 s $(9,4 \%)$. Among the subclass of antivirals, 38 were approved overall, with the most in the 1990s (21, $6 \%$ of all drug approvals) and 2000 s $(13,5 \%)$, and the least in the 1980s (4, 2\%) (Exhibit 1). A majority of these antivirals were antiretroviral drugs for HIV $(\mathrm{n}=24)$. Other antiinfective drug approvals totaled 2 in the 1980 s, 5 in the 1990 s, and 5 in the 2000s, mainly antimycotics and antimycobacterials ( $\mathrm{n}=11$ out of 12 ).

By comparison, during this time period, cardiovascular drugs had the largest number of NME approvals in the 1980 s $(40,18 \%)$, although the number of new cardiovascular drugs fell in the 1990s $(39,12 \%)$ and 2000 s (18, 7\%). Antineoplastic and immunomodulating agents showed a different trajectory, with fewer NME approvals in the 1980s (13, 6\%), but becoming the largest therapeutic class for new approvals in the 1990 s (52, 15\%) and 2000s (51, 20\%) (Exhibit 2). Overall, the number of approvals in all classes peaked in the 1990s but improved slightly from the 1980s to the $2000 \mathrm{~s}(1980 \mathrm{~s}=225 ; 1990 \mathrm{~s}=339 ; 2000 \mathrm{~s}=251)$.
Regulatory Classification of Antiinfectives

In our study period, the FDA approved 57 antiinfectives after priority review $(1980 \mathrm{~s}=16(16 \%$ of all priority reviews), $1990 \mathrm{~s}=24(18 \%), 2000 \mathrm{~s}=17(20 \%))$. Thus, antiinfectives as a class claimed an increasing share of all priority review approvals over time. Within the two largest antiinfective subclasses, priority review antibiotics fell sharply after the 1980 s $(1980 \mathrm{~s}=11(11 \%$ of all priority reviews), $1990 \mathrm{~s}=3(2 \%), 2000 \mathrm{~s}=3(4 \%)$ ), while priority review antivirals grew dramatically to a peak in the 1990 s $(1980 \mathrm{~s}=3$ ( $3 \%$ of all priority reviews), $1990 \mathrm{~s}=17(13 \%), 2000 \mathrm{~s}=11(13 \%))$, most of which were antiretrovirals for HIV ( $\mathrm{n}=22$ ) (Exhibit 3). Overall, $51 \%$ of approved antiinfectives and $28 \%$ of approved antibiotics received priority review, compared to $37 \%$ of drugs approved in all other therapeutic classes.

Orphan drug designation was given at the time of initial FDA approval to 3 antiretrovirals and 3 other antiinfectives during our study period, but none were given to antibiotics. By comparison, 153 drugs overall received orphan drug designation, representing $20 \%$ of all drugs approved after 1983.

\section{Withdrawn Antibiotics}

Among the 61 NME approved antibiotics, 26 were withdrawn ( $43 \%$ ), a rate far higher than was observed among non-antibiotics (13\%). The 26 withdrawn antibiotics are described in Exhibit 4. The mean date from approval to withdrawal was 15 years (interquartile range: 9-19 years). Withdrawals for safetyrelated reasons $(n=6)$ generally occurred sooner after approval, from 4 to 76 months after approval (mean:

Exhibit I

FDA Approvals of New Systemic Antiinfectives, by Class and Subclasses, 1980-2009

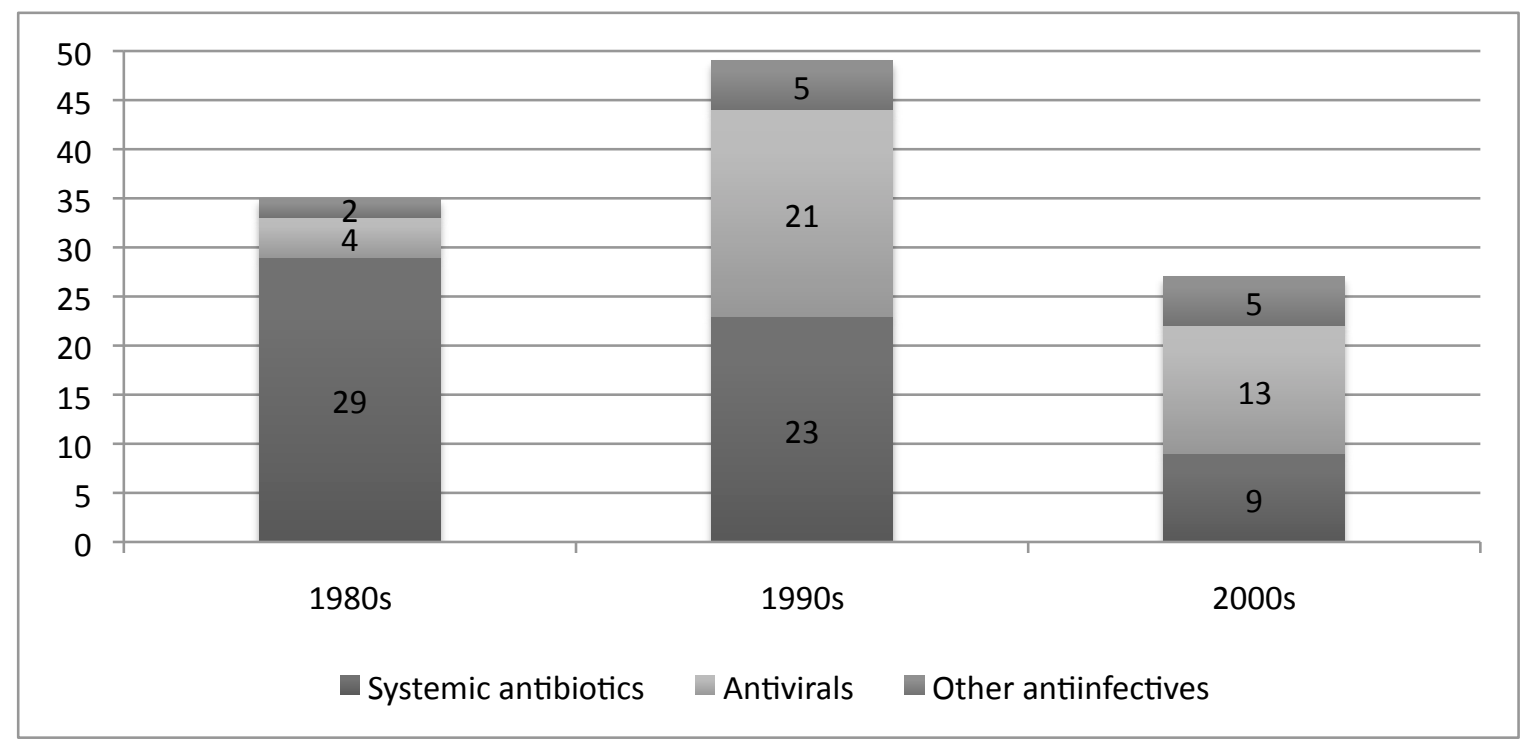


Exhibit 2

FDA Approvals of New Drugs, Percent of Totals, by ATC Class, 1 980-2009

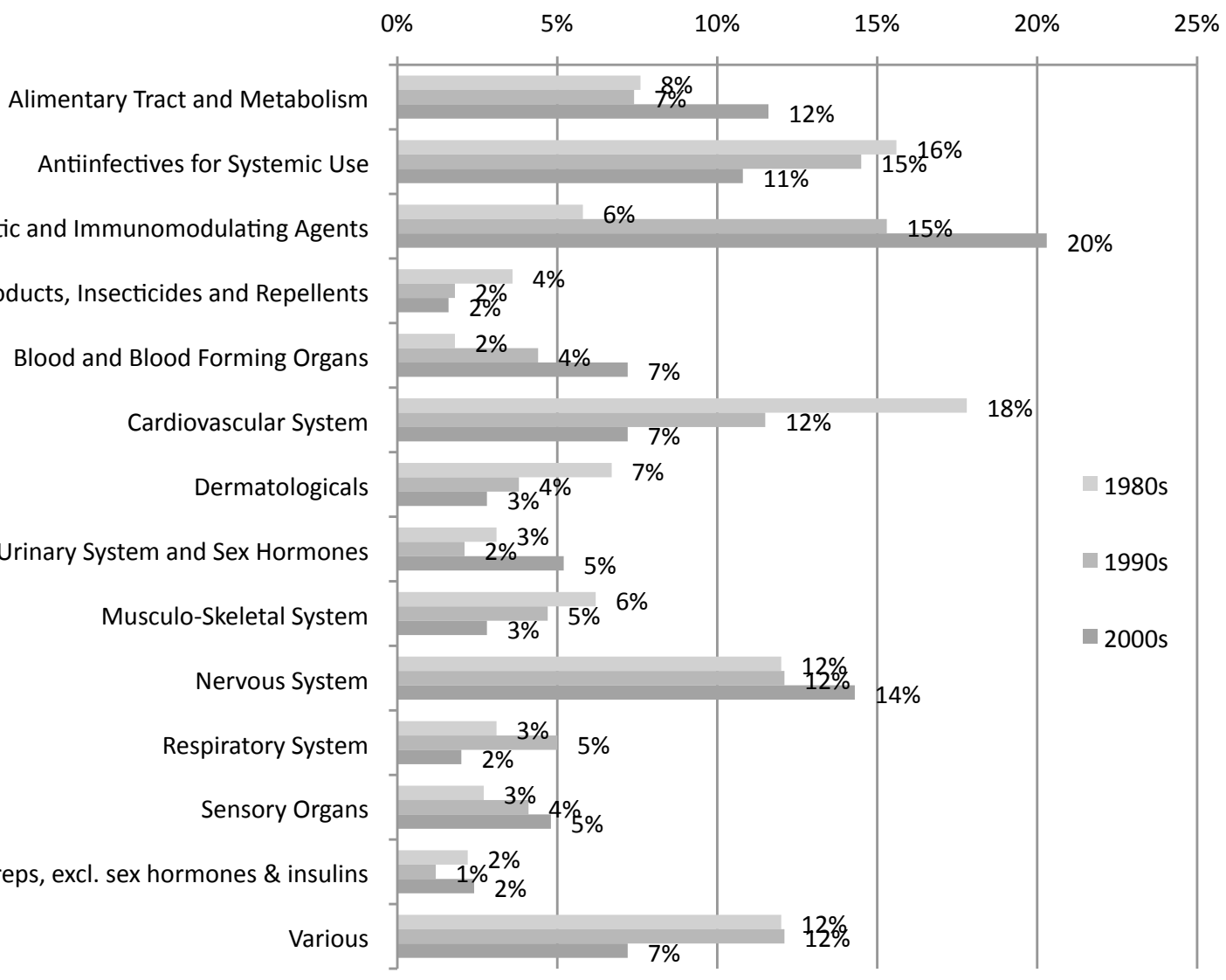

Exhibit 3

FDA Approvals of New Systemic Antiinfectives through Priority Review, I 980-2009

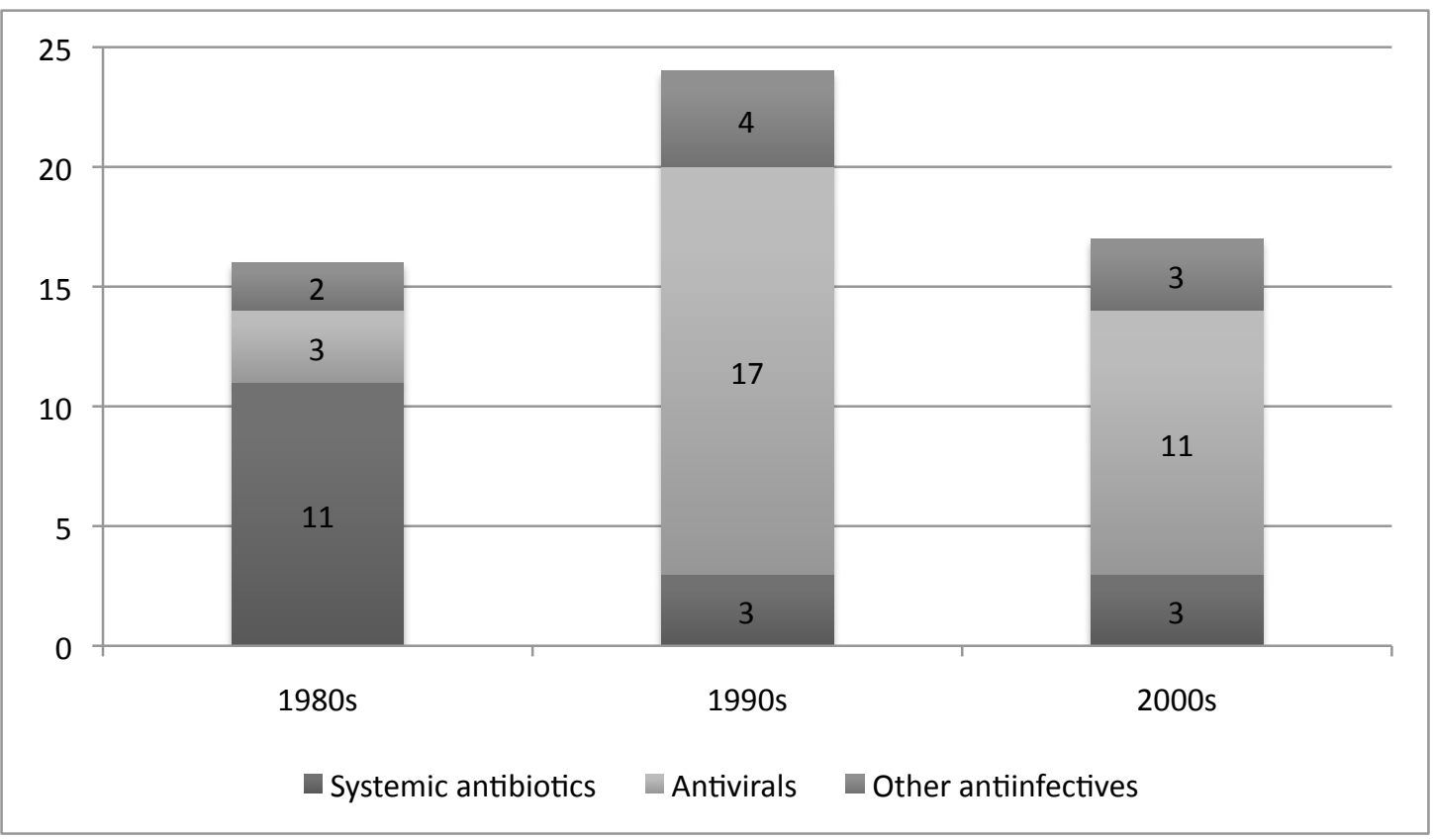


33 months). Withdrawals were greatest for drugs approved in the years 1980-1984 (71\%) and lowest for drugs approved in the years 1985-1989 (33\%). None of the antibiotics approved in the 2000 s was withdrawn as of August 1, 2013.
Our data on antibiotic withdrawals have important policy implications for efforts to incentivize new antibiotic development. Withdrawals among antibiotics in our sample occurred at more than triple the rate of all other drugs. One explanation for this high withdrawal rate is the substantial number of follow-on products approved. In our sample, most withdrawn antibiotics could be generally characterized as secondary or tertiary (or later) drugs in one of two important drug classes: cephalosporins $(n=10)$ and fluoroquinolones $(n=9)$. For example, most of the withdrawn cephalosporins were approved after the introduction of commercially successful first, second, and third generation classes of cephalosporins by other companies (cefadroxil in 1978; cefuroxime in 1987; and ceftriaxone in 1984). Eight of the 9 withdrawn fluoroquinolones were approved after Bayer introduced the blockbuster ciprofloxacin in 1987. To our knowledge, none of the drugs were withdrawn due to emergence of significant antibiotic resistance, as successful drugs with similar resistance profiles remain marketed and widely used. Many antibiotics are approved on the basis of non-inferiority trials, whose primary hypothesis is to rule out how much worse a new antibiotic might be compared to an older antibiotic. ${ }^{17}$ Therefore these studies do not directly measure whether new antibiotics have additional benefits over currently approved therapies. While such sequential innovation can sometimes bring better drugs to market, the high number of sequential innovations later withdrawn after poor sales suggests low levels of clinical significance for these drugs. In a recent review, Pulcini et al. identified 33 "forgotten" antibiotics with potentially significant clinical value, but amongst the 26 withdrawn antibiotics, only cefoperazone appears on their list, and only in combination form with sulbactam. ${ }^{18}$

Priority review status is one ex ante indicator of expected clinical value. ${ }^{19}$ We found that as a class, antiinfectives had more priority review drug approvals than average, with an increasing rate during the past three decades. Over time, priority reviews in the antiinfective class have shifted from antibiotics to antivirals (including antiretrovirals). Few priority review antibiotics were subsequently withdrawn, and none for safety-related reasons. It therefore makes sense to focus antibiotic development incentive programs on particularly novel products that might qualify for priority review. Notably, the GAIN language in the recent Food and Drug Administration Safety and Innovation Act limits its applicability to "serious and life-threatening conditions, ${ }^{, 20}$ which is promising, but 
Exhibit 4

New Systemic Antibiotics Approved by the FDA I 980-2009, but Subsequently Withdrawn or Discontinued

\begin{tabular}{|c|c|c|c|}
\hline Generic Name & Antibiotic class & $\begin{array}{l}\text { Approval } \\
\text { year }\end{array}$ & Withdrawal or Discontinuation Dates \\
\hline Bacampicillin & Penicillin with extended spectrum & 1980 & $\begin{array}{l}\text { Withdrawn from Drug Product List Feb 2006; discontin- } \\
\text { ued before IQ } 1993\end{array}$ \\
\hline Cinoxacin & Fluoroquinolone & 1980 & $\begin{array}{l}\text { Withdrawn as not marketed (Dec 2007); discontinued } \\
\text { before IQ } 1993\end{array}$ \\
\hline Sisomicin & Aminoglycoside & 1980 & $\begin{array}{l}\text { Withdrawn as not marketed (ANDA, Nov 1995); discon- } \\
\text { tinued before IQ } 1993\end{array}$ \\
\hline Mezlocillin & Penicillin with extended spectrum & 1981 & $\begin{array}{l}\text { Withdrawn as not marketed (ANDA, Feb 2002) (NDA, } \\
\text { Mar 2005); discontinued 4Q } 1999\end{array}$ \\
\hline Moxalactam & Third-generation cephalosporin & $1981 *$ & Withdrawn as not marketed (Oct 1996) \\
\hline Azlocillin & Penicillin with extended spectrum & 1982 & $\begin{array}{l}\text { Withdrawn by FDA as not marketed (Sept I997); discon- } \\
\text { tinued before IQ } 1993\end{array}$ \\
\hline Cefoperazone & Third-generation cephalosporin & 1982 & $\begin{array}{l}\text { Withdrawn from the Drug Product List in June 2008; } \\
\text { discontinued 2Q } 2002\end{array}$ \\
\hline Ceftizoxime & Third-generation cephalosporin & 1983 & $\begin{array}{l}\text { Withdrawn as not marketed (Sept 1997); discontinued } \\
\text { 2Q } 2007\end{array}$ \\
\hline Netilmicin & Aminoglycoside & 1983 & $\begin{array}{l}\text { Withdrawn as not marketed (Aug 2003); discontinued } \\
\text { before IQ I993 }\end{array}$ \\
\hline Amdinocillin & Penicillin with extended spectrum & 1984 & $\begin{array}{l}\text { Withdrawn as not marketed (Oct I996); discontinued } \\
\text { before IQ I993 }\end{array}$ \\
\hline Cefonicid & Second-generation cephalosporin & 1984* & $\begin{array}{l}\text { Withdrawn as no longer marketed (Feb 2002); discontin- } \\
\text { ued } 4 \text { Q } 1998\end{array}$ \\
\hline Ceforanide & Second-generation cephalosporin & 1984 & $\begin{array}{l}\text { Withdrawn as not marketed (Aug 2003); discontinued } \\
\text { before IQ I993 }\end{array}$ \\
\hline Cefmenoxime & Third-generation cephalosporin & 1987 & $\begin{array}{l}\text { Withdrawn as not marketed (June 2006); discontinued } \\
\text { before IQ } 1993\end{array}$ \\
\hline Cefotiam & Second-generation cephalosporin & 1988 & $\begin{array}{l}\text { Withdrawn as not marketed (June 1997); discontinued } \\
\text { before IQ } 1993\end{array}$ \\
\hline Cefmetazole & Second-generation cephalosporin & 1989 & $\begin{array}{l}\text { Withdrawn as not marketed (Aug 200I); discontinued } \\
\text { before IQ I993 }\end{array}$ \\
\hline Cefpiramide & Third-generation cephalosporin & 1989 & $\begin{array}{l}\text { Withdrawn as not marketed (Aug 2003); discontinued } \\
\text { before IQ } 1993\end{array}$ \\
\hline Enoxacin & Fluoroquinolone & 1991 & $\begin{array}{l}\text { Withdrawn as not marketed (Mar 2005); discontinued } \\
\text { before Dec. 31, I997 }\end{array}$ \\
\hline Loracarbef & Second-generation cephalosporin & $199 \mid \infty$ & Withdrawn 2006; discontinued 2Q 2006 \\
\hline Lomefloxacin & Fluoroquinolone & 1992 & $\begin{array}{l}\text { Withdrawn from Drug Product List, June 2008; withdrawn } \\
\text { as not marketed (May 2009); discontinued 2Q 200I }\end{array}$ \\
\hline Temafloxacin & Fluoroquinolone & $1992 \dagger$ & Withdrawn June 1992; discontinued 2Q 1992 \\
\hline Dirithromycin & Macrolide & 1995 & $\begin{array}{l}\text { Withdrawn as no longer marketed (Nov 2007); discontin- } \\
\text { ued IQ } 2004\end{array}$ \\
\hline Sparfloxacin & Fluoroquinolone & $1996 t$ & $\begin{array}{l}\text { Withdrawn as not marketed (Mar 2005); discontinued 4Q } \\
2000\end{array}$ \\
\hline Alatrofloxacin & Fluoroquinolone & $1997 \dagger$ & $\begin{array}{l}\text { Withdrawn as not marketed (June 2006); discontinued 4Q } \\
2000\end{array}$ \\
\hline Trovafloxacin & Fluoroquinolone & $1997+\infty$ & $\begin{array}{l}\text { Withdrawn as not marketed (June 2006); discontinued 4Q } \\
2000\end{array}$ \\
\hline Grepafloxacin & Fluoroquinolone & $1997 \dagger$ & $\begin{array}{l}\text { Withdrawn as not marketed (June 2007); discontinued 4Q } \\
\text { I999 }\end{array}$ \\
\hline Gatifloxacin & Fluoroquinolone & $1999+\infty$ & $\begin{array}{l}\text { Withdrawn for reasons of safety or effectiveness (Sept } \\
\text { 2008); discontinued 3Q } 2006\end{array}$ \\
\hline
\end{tabular}

* Granted priority review

† Safety-related withdrawal

$\infty$ Commercially-successful (1993-2009 data only)

Source: Authors' analysis and IMS MIDAS, January 1993-December 2009, IMS Health Incorporated. 
Exhibit 5

New Systemic Antiinfectives Not Withdrawn in the U.S. as of August I, 20 I 3, by Decade of FDA Approval, 1980-2009

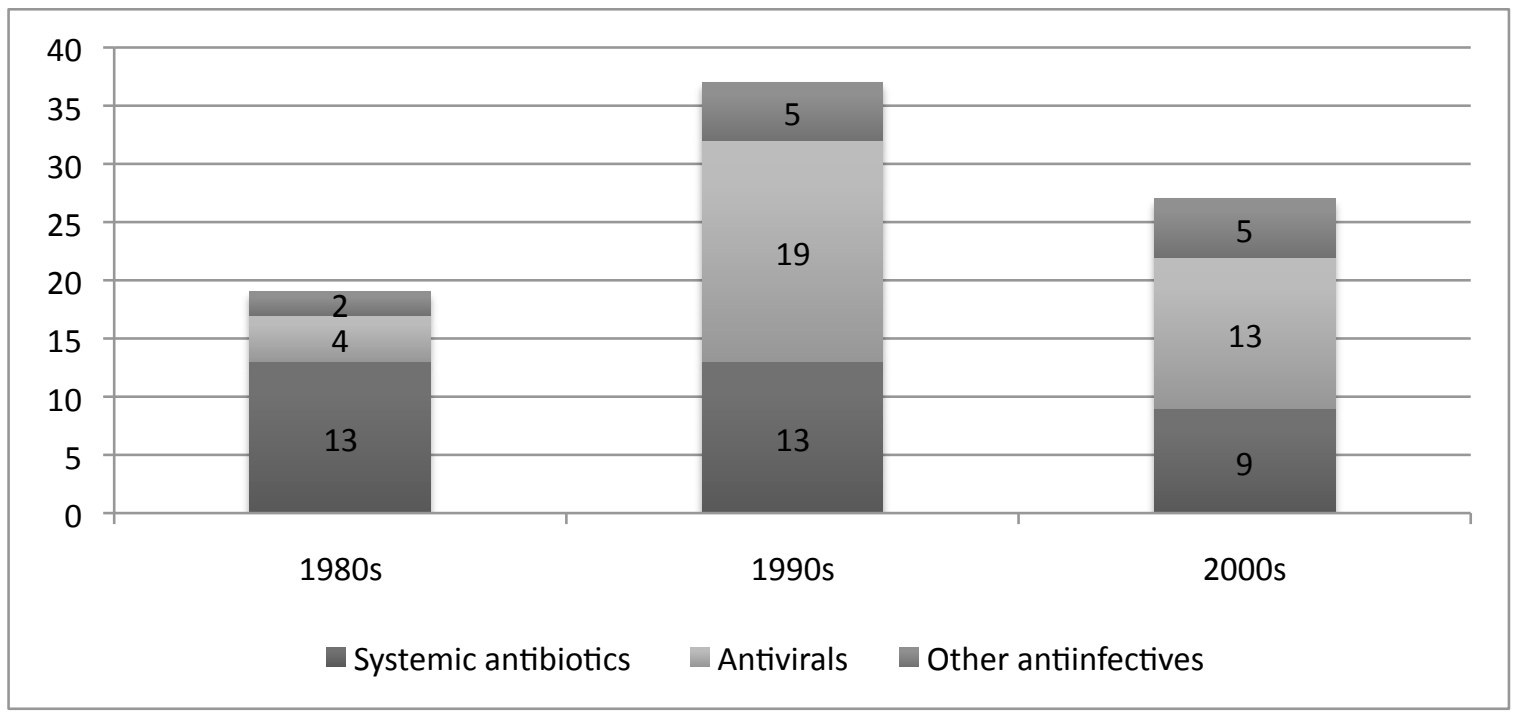

is by definition more inclusive than the priority review program, which is reserved for drugs treating a serious or life-threatening condition that offer patients a significant improvement in safety or effectiveness compared to available therapies.

We found that trends in the rate of antiinfective approvals were comparable to those of other drug classes. For example, while the relative share of approved antiinfective drugs declined, we found that several other classes faced an even sharper drop, including drugs for the cardiovascular system, musculoskeletal system, and skin. In particular, the cardiovascular results are inconsistent with the oft-repeated complaint that antibiotics are uniquely disadvantaged because the course of treatment is short, as compared to long-term maintenance drugs such as those intended to treat high cholesterol or hypertension..$^{21}$ By contrast, the rates of approval of antineoplastic and immunomodulating agents rose substantially, despite the relatively short courses of therapy they often require. Reasons for the growth in antineoplastic drugs may relate to allocations in government funding for basic research, relative scientific progress in therapeutic categories, unmet clinical needs, and the fact that reimbursement levels for cancer drugs have been robust. Indeed, the revenues associated with recent antineoplastic drug development has led commentators to suggest enhancing antibiotic reimbursement as a way of promoting research in this area, including through delinkage mechanisms such as value-based reimbursement and goal-oriented prizes that reward innovation delinked from unit sales. ${ }^{22}$

Finally, our data support the hypothesis that innovation within the antiinfective class shifted from antibiotics to antivirals and antiretrovirals in the last two decades. Given the magnitude of the global HIV/ AIDS epidemic, such a shift might be considered appropriate.

This study has several limitations. The data are limited to NMEs and BLAs, excluding approvals of generic drugs and brand-name drug approvals that are not NMEs. The designation of safety-related withdrawals might be over-inclusive. The literature lacks a clear definition of safety-related withdrawals for antibiotics. ${ }^{23}$ Some researchers have relied on the CDER Annual Reports to exhaustively define the universe of safety-related withdrawals, but these reports rely on agency self-identification of error and may miss subsequent safety-related antibiotic withdrawals. Our designation of safety-related withdrawals might also be under-inclusive. We excluded some withdrawn antibiotics despite known safety issues because the safety issue was not closely enough associated in time to the withdrawal. For example, moxalactam received serious safety warnings but continued with diminished sales for several years before being taken off the market, and was therefore not considered a safety-related withdrawal. Bleeding concerns also are noted in the medical literature with cefoperazone and cefmetazole. ${ }^{24}$ Phototoxicity and 


\section{While there is certainly a need for new antibiotic products to combat evolving resistance among bacteria, policies seeking to remedy a perceived lack of antibiotic innovation should focus on drug quality, not just quantity. The historical data presented here provides evidence that simply emphasizing faster approval of antibiotics based on more limited clinical evidence or stronger intellectual property rights may encourage the approval of products that have limited clinical impact or are subsequently withdrawn from the marketplace for safety or other reasons. Neither represents the type of antibiotic innovation needed today.}

central nervous system effects have been noted with lomefloxacin. ${ }^{25}$ Some antibiotics that were not completely withdrawn had specific indications withdrawn such as telithromycin for acute bacterial sinusitis and acute exacerbations of chronic bronchitis due to lack of evidence of efficacy as well as adverse effects. In addition, the withdrawal data were right censored because we could not capture potential future withdrawals. For example, we did not treat telithromycin as withdrawn since it remained on the market at the time of our analysis although with decreasing usage it may be completely withdrawn in the future. Finally, while the data are analyzed only descriptively, that is consistent with the existing literature on trends in antibiotic approvals.

In conclusion, we found that simple numerical declines in antibiotic approvals give an incomplete picture of drug innovation. Drug approvals are down in many classes, including cardiovascular drugs, so the observed trend may have little to do with antibiotics per se. Nor should policymakers emphasize simple numeric targets without careful focus on the potential clinical value of newly approved agents and their demonstrated benefits over currently available therapies. Numerous antibiotics have suffered from problems after approval, including withdrawals, safety-related withdrawals, and a lack of clinical or commercial significance. While there is certainly a need for new antibiotic products to combat evolving resistance among bacteria, policies seeking to remedy a perceived lack of antibiotic innovation should focus on drug quality, not just quantity. The historical data presented here provides evidence that simply emphasizing faster approval of antibiotics based on more limited clinical evidence or stronger intellectual property rights may encourage the approval of products that have limited clinical impact or are subsequently withdrawn from the marketplace for safety or other reasons. Neither represents the type of antibiotic innovation needed today.

\section{Approval and Withdrawal of New Antibiotics in the U.S., 1980-2009}

\section{List of Exhibits}

Exhibit 1. FDA Approvals of New Systemic Antiinfectives, by Class and Subclasses, 1980-2009

Exhibit 2. FDA Approvals of New Drugs, Percent of Totals, by ATC Class, 1980-2009

Exhibit 3. FDA Approvals of New Systemic Antiinfectives through Priority Review, 1980-2009

Exhibit 4. New Systemic Antibiotics Approved by the FDA 1980-2009, but Subsequently Withdrawn or Discontinued

Exhibit 5. New Systemic Antiinfectives Not Withdrawn in the U.S. as of August 1, 2013, by Decade of FDA Approval, 1980-2009

Acknowledgement

This work was supported by a grant from the Public Health Law Program of the Robert Wood Johnson Foundation. KO was also supported by a grant from the David Saul Smith Foundation.

\section{References}

1. M. Lipsitch and M. H. Samore, "Antimicrobial Use and Antimicrobial Resistance: A Population Perspective," Emerging Infectious Disease 8, no. 4 (2002): 347-354; E. Klein, D. L. Smith, and R. Laxminarayan, "Hospitalizations and Deaths Caused by Methicillin-Resistant Staphylococcus Aureus, United States, 1999-2005," Emerging Infectious Disease 13, no. 12 (2007): 1840-1846; F. Baquero, T. M. Coque, F. de la Cruz, "Ecology and Evolution as Targets: The Need for Novel Eco-Evo Drugs and Strategies to Fight Antibiotic Resistance," Antimicrobial Agents and Chemotherapy 55, no. 8 (2011): 3649-3660.

2. A. S. Kesselheim and K. Outterson, "Fighting Antibiotic Resistance: Marrying New Financial Incentives to Meeting Public Health Goals," Health Affairs 29, no. 9 (2010): 1689-1696; R. Laxminarayan and A. Malani, "Extending the Cure: Policy Responses to the Growing Threat of Antibiotic Resistance," Resources for the Future, 2007, available at $<\mathrm{http}$ // /www.extendingthecure.org/report> (last visited July 26, 2013); A. S. Kesselheim and K. Outterson, "Improving Antibiotic Markets for Long Term Sustainability," Yale Journal of Health Policy, Law and Ethics 11, no. 1 (2011): 101-167; K. Outterson, J. B. Samora, and K. Keller-Cuda, "Will Longer Antimicrobial Patents Improve Global 
Public Health?" The Lancet Infectious Disease 7, no. 8 (2007): 559-566; A. D. So, N. Gupta, S. K. Brahmachari, I. Chopra, B. Munos, C. Nathan, K. Outterson, J. P. Paccaud, D. J. Payne, R. W. Peeling, M. Spigelman, and J. Weigelt, "Towards New Business Models for R\&D for Novel Antibiotics," Drug Resistance Updates 14, no. 2 (2011): 88-94.

3. See $i d$. (Kesselheim and Outterson, 2010); $i d$. (Laxminarayan and Malani); $i d$. (Kesselheim, and Outterson, 2011); $i d$. (Outterson, Samora, and Keller-Cuda); $i d$. (So et al.); "Policy Statement on Antimicrobial Stewardship by the Society for Healthcare Epidemiology of America (SHEA), the Infectious Diseases Society of America (IDSA), and the Pediatric Infectious Diseases Society (PIDS)," Infection Control and Hospital Epidemiology 33, no. 4 (2012): 322-327 [hereinafter cited as Policy Statement].

4. See supra note 2 .

5. ECDC/EMEA, Joint Technical Report: The Bacterial Challenge: Time to React - A Call to Narrow the Gap between MultidrugResistant Bacteria in the EU and the Development of Nere Antibacterial Agents (2009), available at <http://www.ema. europa.eu/docs/en_GB/document_library/Report/2009/11/ WC500008770.pdf $>$ (last visited July 29, 2013); B. Spellberg, J. H. Powers, E. P. Brass, L. G. Miller, and J. E. Edwards, Jr., "Trends in Antimicrobial Drug Development: Implications for the Future," Clinical Infectious Diseases 38, no. 9 (2004): 12791286; Infectious Diseases Society of America, Bad Bugs, No Drugs: As Antibiotic Discovery Stagnates... a Public Health Crisis Breres (2004), available at <http://www.idsociety.org/uploadedFiles/IDSA/Policy_and_Advocacy/Current_Topics_and_Issues/ Antimicrobial_Resistance/10x20/Images/Bad\%20Bugs $\% 20$ no\%20Drugs.pdf $>$ (last visited July 29, 2013); L. Freire-Moran, B. Aronsson, C. Manz, I. C. Gyssens, A. D. So, D. L. Monnet, O. Cars, ECDC-EMA Working Group, "Critical Shortage of New Antibiotics in Development against Multidrug-Resistant Bacteria - Time to React Is Now," Drug Resistance Updates 14, no. 2 (2011): 118-124; Swedish Presidency of the European Union, Innovative Incentives for Effective Antibacterials, Stockholm, Sweden, September 17, 2009, available at $<\mathrm{http}: / /$ www.lakemedelsverket.se/upload/nyheter/2009/Rapport $\% 20$ fr\%C3\%A5n\%20m\%C3\%B6tet.pdf> (last visited August 14, 2013); S. J. Projan, "Why Is Big Pharma Getting Out of Antibacterial Drug Discovery?" Current Opinion in Microbiology 6, no. 5 (2003): 427-430.

6. Id. (Projan); B. Munos, "Lessons from 60 Years of Pharmaceutical Innovation," Nature Revieres Drug Discovery 8, no. 12 (2009): 959-968.

7. See Policy Statement, supra note 3; F. Allerberger, R. Gareis, V. Jindrak, and M. J. Struelens, "Antibiotic Stewardship Implementation in the EU: The Way Forward," Expert Reviere of AntiInfective Therapy 7, no. 10 (2009): 1175-1183.

8. See ECDC/EMEA, supra note 5; Spellberg et al., supra note 5; Infectious Diseases Society of America, supra note 5; FreireMoran et al., supra note 5; Swedish Presidency of the European Union, supra note 5.

9. See K. Outterson, "All Pain; No GAIN: Need for Prudent Antimicrobial Use Provisions to Complement the GAIN Act," Alliance for the Prudent Use of Antibiotics (APUA) Clinical Newsletter 30, no. 1 (2012): 13-15.

10. $I d$.

11. See ECDC/EMEA, supra note 5; Freire-Moran et al., supra note 5; Swedish Presidency of the European Union, supra note 5; T. Kirby, "Europe to Boost Development of New Antimicrobial Drugs," The Lancet 379, no. 9833 (2012): 2229-2230; E. Mossialos, C. M. Morel, S. Edwards, J. Berenson, M. Gemmill-Toyama, and D. Brogan, Policies and Incentive for Promoting Innovation in Antibiotic Research, 2010 World Health Organization, on behalf of the European Observatory on Health Systems and Policies, available at <http://www.euro.who.int/_data/assets/ pdf file/0011/120143/E94241.pdf> (last visited July 29, 2013).

12. K. Outterson, J. H. Powers, I. M. Gould, and A. S. Kesselheim, "Questions about the $10 \mathrm{x}$ '20 Initiative," Clinical Infectious Diseases 51, no. 6 (2010): 751-752.

13. FDA, "Drugs@FDA," available at <http://www.accessdata.fda. gov/scripts/cder/drugsatfda/> (last visited August 14, 2013).
14. WHO Collaborating Centre for Drug Statistics Methodology, "Structure and Princples," available at <http://www.whocc.no/ atc/> (last visited August 14, 2013).

15. Z. P. Qureshi, E. Seoane-Vazquez, R. Rodriguez-Monguio, K. B. Stevenson, and S. L. Szeinbach, "Market Withdrawal of New Molecular Entities Approved in the United States from 1980 to 2009," Pharmacoepidemiology and Drug Safety 20 (2011): 772-777.

16. FDA/CDER/Office of Surveillance and Epidemiology, Levaquin (Levofloxacin) Oral Solution, $250 \mathrm{mg} / 10 \mathrm{ml}$ BPCA Drug Use Review, July 10, 2008, available at <http://www.fda.gov/ ohrms/dockets/ac/08/briefing/2008-4399b1-12\%20(Levaquin $\% 20$ (levofloxacin)\%20Use $\% 20$ Review).pdf> (last visited July 29, 2013); D. K. Wysowski and L. Swartz, "Adverse Drug Event Surveillance and Drug Withdrawals in the United States, 1969-2002: The Importance of Reporting Suspected Reactions," Archives of Internal Medicine 165, no. 12 (2005): 1363-1369; P. Olivier and J. L. Montastruc, "The Nature of the Scientific Evidence Leading to Drug Withdrawals for Pharmacovigilance Reasons in France," Pharmacoepidemiology and Drug Safety 15, no. 11 (2006): 808-812; J. Lexchin, "Drug Withdrawals from the Canadian Market for Safety Reasons, 1963-2004," CMAJ 172, no. 6 (2005): 765-767; H. H. Liu, "Safety Profile of the Fluoroquinolones: Focus on Levofloxacin," Drug Safety 33, no. 5 (2010): 353369; A. M. Issa, K. A. Phillips, S. Van Bebber, H. G. Nidamarthy, K. E. Lasser, J. S. Haas, B. K. Alldredge, R. M. Wachter, and D. W. Bates, "Drug Withdrawals in the United States: A Systematic Review of the Evidence and Analysis of Trends," Current Drug Safety 2, no. 3 (2007): 177-185; O. M. Bakke, M. Manocchia, F.de Abajo, K. I. Kaitin, and L. Lasagna, "Drug Safety Discontinuations in the United Kingdom, the United States, and Spain from 1974 through 1993: A Regulatory Perspective," Clinical Pharmacology $\Xi 5$ Therapeutics 58, no. 1 (1995): 108-17.

17. US Government Accountability Office, FDA's Consideration of Evidence from Certain Clinical Trials, July 2010, available at <http://www.gao.gov/assets/310/308301.pdf> (last visited August 14, 2013); FDA, Guidance for Industry, Antibacterial Drug Products: Use of Noninferiority Trials to Support Approval, November 2010, available at <http://www.fda.gov/downloads/ Drugs/GuidanceComplianceRegulatoryInformation/Guidances/ UCM070951.pdf> (last visited August 14, 2013).

18. C. Pulcini, K. Bush, W. A. Craig, N. Frimodt-Moller, M. Grayson, J. W. Mouton, J. Turnidge, S. Harbarth, and I. C. Gyssens, "ESCMID Study Group for Antibiotic Policies. Forgotten antibiotics: an inventory in Europe, the United States, Canada, and Australia," Clinical Infectious Diseases 54, no. 2 (2012): 268-274.

19. M. Hunt, Changing Patterns of Pharmaceutical Innovation (May 2002), National Institute for Health Care Management (NIHCM) Research and Educational Foundation, available at $<$ http://www.nihcm.org/pdf/innovations.pdf> (last visited July 29, 2013).

20. See Outterson, supra note 9.

21. See Projan, supra note 5.

22. See Kesselheim and Outterson (2010), supra note 2; Laxminarayan and Malani, supra note 2; Kesselheim and Outterson (2011), supra note 2; Outterson, Samora, and Keller-Cuda, supra note 2; So et al., supra note 2; J. Love, Knowledge Ecology International, "Prizes to Stimulate Innovation," available at <http:// keionline.org/prizes> (last visited August 14, 2013).

23. See Qureshi et al., supra note 15; see FDA/CDER/Office of Surveillance and Epidemiology, supra note 16; Wysowski and Swartz, supra note 16; Olivier and Montastruc, supra note 16; Lexchin, supra note 16; Liu, supra note 16; Issa et al., supra note 16; Bakke et al., supra note 16.

24. G. A. Breen and W. L. St. Peter, "Hypoprothrombinemia Associated with Cefmetazole," Annals of Pharmacotherapy 31, no. 2 (1997): 180-184; J. J. Lipsky, "Antibiotic-Associated Hypoprothrombinemia," Journal of Antimicrobial Chemotherapy 21 (1988): 281-300; R. B. Brown, J. Klar, and S. Lemeshow et al., "Enhanced Bleeding with Cefoxitin and Moxalactam," Archives of Internal Medicine 146 (1986): 2159-2164.

25. E. Rubinstein, "History of Quinolones and Their Side Effects," Chemotherapy 47, Supp. 3 (2001): 3-8. 